\title{
Review
}

\section{Complementary and Alternative Medicine in Pakistan: Prospects and Limitations}

\author{
Babar T. Shaikh ${ }^{1}$ and Juanita Hatcher ${ }^{2}$ \\ ${ }^{1}$ Health Systems Division and ${ }^{2}$ Community Health Sciences Research Development Office, Department of \\ Community Health Sciences, Aga Khan University, Karachi, Pakistan
}

\begin{abstract}
Despite all the marvelous advancements in modern medicine, traditional medicine has always been practiced. More than $70 \%$ of the developing world's population still depends on the complementary and alternative systems of medicine (CAM). Cultural beliefs and practices often lead to self-care or home remedies in rural areas and consultation with traditional healers. Evidence-based CAM therapies have shown remarkable success in healing acute as well as chronic diseases. Alternative therapies have been utilized by people in Pakistan who have faith in spiritual healers, clergymen, hakeems, homeopaths or even many quacks. These are the first choice for problems such as infertility, epilepsy, psychosomatic troubles, depression and many other ailments. The traditional medicine sector has become an important source of health care, especially in rural and tribal areas of the country. The main reasons for consulting a CAM healer is the proximity, affordable fee, availability, family pressure and the strong opinion of the community. Pakistan has a very rich tradition in the use of medicinal plants for the treatment of various ailments. It necessitates the integration of the modern and CAM systems in terms of evidence-based information sharing. The health-seeking behavior of the people especially in developing countries calls for bringing all CAM healers into the mainstream by providing them with proper training, facilities and back-up for referral. A positive interaction between the two systems has to be harnessed to work for the common goal of improving health of the people.
\end{abstract}

Keywords: alternative medicine - complementary medicine - health care system - health-seeking behavior - Pakistan

\section{Introduction}

For centuries, man has used self-coined traditional means for treating for ailments, and continues to use them along side modern medicine even today. Despite all the marvelous advancements in modern medicine, traditional medicine has always been practiced. Traditional medicine refers to health practices, approaches, knowledge and beliefs incorporating plant-, animal- and mineral-based medicines, spiritual therapies, manual techniques and exercises, applied singly or in combination to treat, diagnose and prevent illnesses or maintain well-being (1). This domain has taken the new name complementary and alternative medicine (CAM). CAM refers to

For reprints and all correspondence: Dr Babar T. Shaikh, Senior Instructor, Health Systems Division, Department of Community Health Sciences, Aga Khan University, PO Box 3500, Karachi, Pakistan. Tel: +92-21-4930051 ext: 4899, 4811 Fax: +92-21-4934294, 4932095; E-mail: babar.shaikh@aku.edu those therapeutic and diagnostic disciplines that exist largely outside the institutions where conventional health care is provided (2). There has been an unprecedented increasing interest in these systems of therapeutics on a global level (3). According to one estimate, $>80 \%$ of the developing world's population still depends on the complementary and alternative systems of medicine, while about half of the population in industrialized countries use CAM (4). It has always been an 'invisible mainstream' within the health care delivery system (5). The Alma-Ata declaration in 1978 particularly said that mobilization of traditional medicine systems is an important way to make health for all a reality $(6,7)$. The reasons for the inclusion of CAM healers in primary health care are manyfold: the healers know the socio-cultural background of the people; they are highly respected and experienced in their work; economic considerations; the distance to be covered in some countries; the strength of traditional beliefs; the shortage of

(C) The Author (2005). Published by Oxford University Press. All rights reserved.

The online version of this article has been published under an open access model. Users are entitled to use, reproduce, disseminate, or display the open access version of this article for non-commercial purposes provided that: the original authorship is properly and fully attributed; the Journal and Oxford University Press are attributed as the original place of publication with the correct citation details given; if an article is subsequently reproduced or disseminated not in its entirety but only in part or as a derivative work this must be clearly indicated. For commercial re-use, please contact journals.permissions@oupjournals.org 
modern health professionals, etc. (3). Evidence-based CAM therapies have shown remarkable success in healing acute as well as chronic diseases. It is strongly believed that various CAM therapies function and heal through their influence on the immune system of the human body (8).

Health care utilization depends on health-seeking behavior which in turn is a product of various factors: physical, socioeconomic, cultural and political $(9,10)$. Cultural beliefs and practices often lead to self-care or home remedies in rural areas and consultation with traditional or CAM healers (11). These factors at times result in a delay in treatment seeking and are more common not only for their own health but especially for children's illnesses $(12,13)$. Use of CAM for gynecological problems amongst women is also common to all cultures (14). These cultural practices and beliefs have been prevalent regardless of age (15), socio-economic status of the family and level of education $(16,17)$. At times, these beliefs also affect awareness and recognition of the severity of illness as well as acceptability of the service $(18,19)$. In addition, the cooperation, empathetic attitude and active listening offered by the traditional healer attract more clientele as compared with modern allopathic practitioners (20).

Here we review the factors shaping a typical health-seeking behavior on use of complementary, traditional and alternative health services in Pakistan. We also discuss the prospects and limitations of integrating the alternative medical services with modern services.

\section{Situation in Pakistan}

In Pakistan, over half the population (66\%) lives in the rural part of the country (21). Poverty, compounded by illiteracy, low status of women, and inadequate water and sanitation facilities, has had a deep impact on health indicators (22). Limited knowledge of health and disease, cultural and household remedies, perceptions of a health service and provider and social barriers, and the cost related to the provision of an effective health service have been the major barriers $(23,24)$. The health care system in Pakistan has two main divisions: the public domain and the private domain. The public sector, which is regulated and recognized but mainly composed of an allopathic system of health care, is severely under-utilized due to certain weaknesses including insufficient focus on prevention and promotion of health, excessive centralization of management, political interference, lack of openness, weak human resource development, lack of integration and lack of a public health policy $(25,26)$. In the private sector, there are very few accredited outlets and hospitals, but many unregulated hospitals, medical general practitioners, homeopaths, hakeems, traditional/spiritual healers, Unani (Greco-arab) healers, herbalists, bonesetters and quacks (27). The type of symptoms experienced for the illness and the number of days of illness are major determinants of healthseeking behavior and choice of care provider. In the case of a mild single symptom such as fever, home remedies or folk prescriptions are used, whereas with multiple symptoms and a longer period of illness, a biomedical health provider is more likely to be consulted (25). Alternative therapies have been utilized by people having faith in spiritual healers, clergymen, hakeems, homeopaths or even many quacks. These are the first choice for problems such as infertility, epilepsy, psychosomatic troubles, depression, etc. (28). Other reasons for consulting a CAM healer are the proximity, affordable fee, availability of the provider, family pressure and the strong opinion of the community. The literature reveals that the patients who use allopathic medicines as well as alternative medicines concomitantly are reluctant to reveal to their allopathic physician that they are also using alternative medicines (29). This communication barrier augments the risk of developing complications from the combination of allopathic and alternative therapy.

\section{Prospects}

The herbal or 'Unani' or Greco-arab system of medicine is a growing industry worldwide. Global sales of herbal products now exceed a staggering US $\$ 40$ billion a year (30). Pakistan has a very rich tradition in the use of medicinal plants for the treatment of various ailments, based predominantly on the Unani system of medicine, which dates back to the Indus valley civilization (31). This traditional medicine sector has become an important source of health care, especially in rural and tribal areas of the country (32). Most of the medicinal plants are found in the temperate climates and subtropical forests of northern Pakistan (33). Around 70-80\% of the population, particularly in rural areas, uses CAM (32). In addition to other CAM systems such as Ayurvedic and homeopathic, the Unani system has been accepted and integrated into the national health system. Pakistan is the only country in the eastern Mediterranean region where formal Unani teaching institutions are recognized (33). There has been significant movement at the policy level in terms of CAM regulation. The government of Pakistan has in place a number of organizations and initiatives aimed at strengthening and coordinating various aspects of the sector, supplemented by non-government and private sector initiatives. However, stronger coordination of the sector at the national level under a strategic plan is imperative, which will produce offshoots into research and development (34). There are 45000 traditional healers, of whom about three-quarters are practicing in rural areas (35). The presence of these practitioners in rural areas may be regarded as a source of health care delivery for the rural majority of Pakistan. Approximately 52600 registered Unani medical practitioners are practicing both in the public and private sector in urban and rural areas. About 360 tibb dispensaries and clinics provide free medication to the public under the control of the health departments of provincial governments (33). There is a definite need to design training and capacity-building programs for the CAM practitioners who need such continuing education, hence bringing them into the mainstream and elevating their status in society.

As for herbal medicine, Pakistan is among the eight leading exporters of medicinal plants (32). There is need to build partnerships at various levels. A coalition may be developed on the basis of shared primary interest at the regional and global 
level. For instance, conservation and sustainable utilization of resources can be achieved through community participation. Non-governmental organizations need to be involved in bio-prospecting and benefit sharing (35). A true partnership would make an invaluable contribution towards achieving the goals of environmental and biodiversity conservation; and an increased share of international trade in raw materials relating to medicinal plants. This would require the implementation of government policies and incentives for the exporters (36). A close collaboration among all stakeholders including allopathic practitioners, traditional medicine practitioners, ethnobotanists, phytochemists, pharmacologists, agricultural experts and other related disciplines would be encouraging.

\section{Limitations}

The relationship between the conventional allopathic physician and the CAM provider is of rivalry and animosity, just as happens in any other part of the world (36). Orthodox medicine has never been in favor of traditional medicine; therefore, these practices are denounced vigorously by restricting their access, labeling them as antiscientific and imposing penalties on their practice. Some understandable factors for this rejection include lack of education, training, regulation and the evidence base for CAM practitioners. Moreover, lack of accountability in the medical profession, both modern and complementary, results in untrained quacks practicing medicine in different names, thus giving CAM practitioners a bad name and lowering respect for them in the community. In terms of political economy, the allopathic system of cure is a British colonial legacy that retained influence on the entire health care system of the country. With this elite-backed system, the attitude of looking down on the indigenous systems has been coupled with an established antagonism between the practitioners of the two systems (37). Current evidence, although limited, suggests that physicians may reasonably accept some CAM therapies as adjuncts to conventional care and discourage others. The National health policy of Pakistan just mentions a plan to bring amendment to the existing law on tibb to recognize the post-graduate level education; however, the stance on its integration or development is unclear (38). Other policy documents bear certain lacunae on profit sharing, intellectual property rights, registration of herbal products and other related legislation (35). The CAM therapies being used have not been thoroughly researched, and by and large there is only evidence from old documents. Furthermore, indigenous people have no training in gathering and storing of medicinal plants, and hence the sustainability of such plants is threatened. The indigenous knowledge of identification and use of medicinal herbs is dying out. Deforestation and threat of extinction is also alarming because the area covered by forests is decreasing day by day due to lack of water and repeated droughts.

\section{The Way Forward}

To develop a balanced health policy to provide efficient and acceptable health services, we need to understand the diversity of health-seeking behavior of the population in the pluralistic health care system of Pakistan. People have been consulting traditional healers for ages and they will keep on doing so for various reasons. The solution lies only in bringing these CAM healers into the mainstream by providing them with proper training, facilities and back-up for referral. The state regulatory authorities have a crucial role to play in this scenario, in terms of recognition of CAM, financing and appreciating training and research in this field. The inclusion of some introductory modules of CAM into the medical curriculum of allopathic medical schools may be considered. A positive interaction between all cadres of health providers, academicians, policy makers and researchers has to be harnessed to work for a common goal to improve the health of the people. It is important to note that as the global use of healing practices outside conventional medicine is on the increase, ignorance about these practices by physicians and scientists risks broadening the communication gap between the public and the profession that serves them $(39,40)$. This necessitates the integration of the two systems at least in terms of evidence-based information sharing. It would also be worthwhile to emphasize that regular systematic reviews of CAM therapies are imperative in the process of recognizing the CAM sector. In the rush to achieve ambitious and gigantic targets in Millennium Development Goals, gross improvements in quality and efficacy of medical care would require strengthening and integration of public health programs (41). Evidencebased CAM could be cost-effective for the people of developing countries and, more importantly, the outcomes of the treatments could be very efficacious (42). Moreover, financial allocation and distribution on the basis of research and evidence would be another important change to bring about in order to reduce the disease burden. Through more rigorous research, the evidencebased recommendation of some CAM therapies and the evidence-based rejection of others will become more definitive (43). Today, in the West, there is an overwhelming effort towards integration of alternative medicine with the mainstream allopathic therapeutics (31). However, before this can be done, research into CAM itself needs to be recognized as a mainstay to design any public health interventions (44). Guidelines for policy formulation, regulation, promotion and development of traditional medicine need to be developed. With the current state of affairs of health system utilization and health-seeking behavior in Pakistan, it is highly desirable to reduce the polarization in health system utilization by exploring more opportunities for integration of traditional and modern medicine.

\section{References}

1. World Health Organization. Traditional Medicine, Fact Sheet No. 134, September 1996, URL. http://www.who.int/mediacentre/factsheets/fs134/en/ [accessed on 6/12/2004]

2. Zollman C, Vickers A. ABC of complementary medicine: what is complementary medicine? Br Med J 1999;319:693-6.

3. World Health Organization. Traditional Medicine Strategy 2002-2005. Geneva: WHO, 2001.

4. Bodeker G, Kronenberg F. A Public health agenda for traditional, complementary, and alternative medicine. Am J Publ Health 2002;92: $1582-91$. 
5. Penson RT, Castro CM, Seiden MV, Chabner BA, Lynch TJ Complementary, alternative, integrative, or unconventional medicine? Oncologist 2001;6:463-73.

6. Declaration of Alma-Ata. International Conference on Primary Health Care. Alma-Ata, USSR, 6-12 September, 1978.

7. Balasubramaniam K. Neglect of traditional medicines: a mistake. China Daily 20 February, 2001.

8. Tada T. Towards the philosophy of CAM: super-system and epimedical sciences. eCAM 2004;1:5-8.

9. Kroeger A. Anthropological and socio-medical health care research in developing countries. Soc Sci Med 1983;17:147-61.

10. Fatimi Z, Avan I. Demographic, Socio-economic and environmental determinants of utilization of antenatal care in rural setting of Sindh, Pakistan. J Pak Med Assoc 2002;52:138-142.

11. Nyamongo IK. Health care switching behavior of malaria patients in a Kenyan rural community. Soc Sci Med 2002;54:377-86.

12. Nakagawa YM et al. Gender difference in delays to diagnosis and health care seeking behavior in a rural area of Nepal. Int J Tuberc Lung Dis 2001;5:24-31.

13. McNee A et al. Responding to cough: Boholano illness classification and resort to care in response to childhood ARI. Soc Sci Med 1995;40: 1279-89.

14. Beal MW. Women's use of alternative and complementary therapies in reproductive health care. J Nurse Midwifery 1998;43:224-34.

15. Geissler PW et al. Children and medicines: self treatment of common illnesses among Luo schoolchildren in western Kenya. Soc Sci Med 2000; 50:1771-83.

16. Stuyft PV, Sorenson SC, Delgado E, Bocaletti E. Health seeking behavior for child illness in rural Guatemala. Trop Med Int Health 1996;1:161-70.

17. Perez-Cuevas R et al. Mother's health seeking behavior in acute diarrhea in Tlaxcala, Mexico. J Diarrhoeal Dis Res 1996;14:260-8.

18. Aday LA, Anderson R. A framework for the study of access to medical care. Health Serv Res 1974;9:208-20.

19. Hasan IJ, Khanum A. Health care utilization during terminal illness in squatter settlements. J Pak Med Assoc 2002;50.

20. Stekelenburg J, Jager BE, Kolk PR, Westen EHMN, van der Kwaak A. Wolffers IN. Health care seeking behaviour and utilization of traditional healers in Kalabo, Zambia. Health Policy 2005;71:67-81.

21. Population Reference Bureau. 2003 Population Data Sheet. Washington, DC: Population Reference Bureau, 2003.

22. World Bank. Pakistan Poverty Assessment. Poverty in Pakistan: Vulnerabilities, Social Gaps, and Rural Dynamics. Islamabad: Poverty Reduction and Economic Management Sector Unit, South Asia Region, 2002.

23. Hunte P, Sultana F. Health seeking behavior and the meaning of medications in Balochistan, Pakistan. Soc Sci Med 1992;34:1385-97.

24. Karim MS. Socio-economic, Demographic and Health Situation in Thatta District. Karachi: Department of Community Health Sciences, Aga Khan University. 1987.

25. World Bank. Towards a Health Sector Strategy. Washington, DC: Health, Nutrition \& Population Unit, South Asia Region, 1997.
26. Khan A. Policy making in Pakistan's population programme. Health Policy Plan 1996;11:30-51.

27. Karim MS, Mahmood MA. Health Systems in Pakistan: A Descriptive Analysis. Karachi: Department of Community Health Sciences, Aga Khan University, 1999.

28. Renckens CNM. Alternative treatments in reproductive medicine: much ado about nothing. Hum Reprod 2002;17:528-33.

29. Dunn L, Perry B. Where your patients are? Prim Care 1997;24:715-21.

30. Gilani A. Prospects of Traditional Medicine in Pakistan. In: Proceedings of the International Seminar on Integration of Traditional Medicine (Complementary/Alternative) and Modern Medicine, Cairo, 2002.

31. World Health Organization. Legal Status of Traditional Medicine and Complementary and Alternative Medicine: A World Review. Geneva: WHO, 2001.

32. Hussain. SA, Saeed. A, Ahmed. M, Qazi. A. Contemporary role and future prospects of medicinal plants in the health care system and pharmaceutical industries of Pakistan. URL http://www.telmedpak.com/doctorsarticles. [accessed on 6/12/2004].

33. Rahman AU. Bioprospecting of Medicinal and Food Plants: Pakistan. UNDP, New York: Special Unit for South-South Cooperation, 2003.

34. Williams JT, Ahmad Z. Priorities for Medicinal Plants Research and Development in Pakistan. Ottawa: International Development Research Center, 2004.

35. Gilani A. Phytotherapy - the role of natural products in modern medicine. J Pharm Med 1992;2:111-8.

36. Fink S. International efforts spotlight traditional, complementary, and alternative medicine. Am J Publ Health 2002;92:1734-9.

37. Zaidi SA. Issues in the health sector in Pakistan. In: The Political Economy of Health Care in Pakistan. Lahore: Vanguard Books (Pvt) Ltd, 1988,3 .

38. Government of Pakistan. National Health Policy: The Way ForwardAgenda for Health Sector Reform. Islamabad: Ministry of Health, 2001.

39. Wetzel M, Eisenberg. D, Kaptchuk. T. Courses involving complementary and alternative medicine at US medical schools. J Am Med Assoc 1998; 280:784-7.

40. Chez I, Jonas W. The challenge of complementary and alternative medicine. Am J Obstet Gynecol 1997;177:1156-61.

41. World Bank. The Millennium Development Goals for Health: Rising to the Challenges. Washington, DC, 2004.

42. Cooper EL. Complementary and alternative medicine, when rigorous, can be science. eCAM 2004;1:1-4.

43. Eisenberg DM, Ted J, Kaptchuck T. Advising patients who seek complementary and alternative therapies for cancer. Ann Intern Med 2002;137: 889-903.

44. Travis $\mathrm{P}$, Bennette $\mathrm{S}$, Haines A et al. Overcoming health systems constraints to achieve the Millennium Development Goals. Lancet 2004;364: 900-6.

Received December 10, 2004; revised on February 9, 2005; accepted on March 28, 2005 


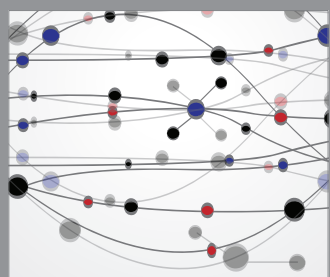

The Scientific World Journal
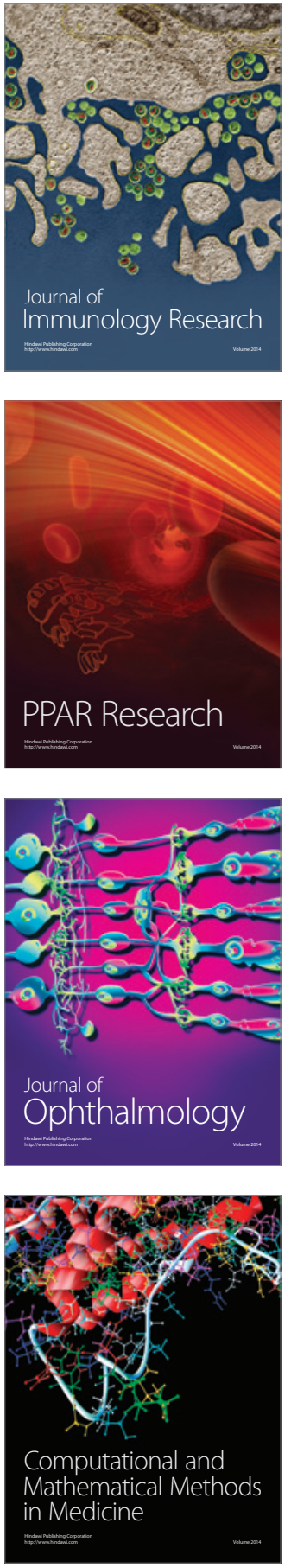

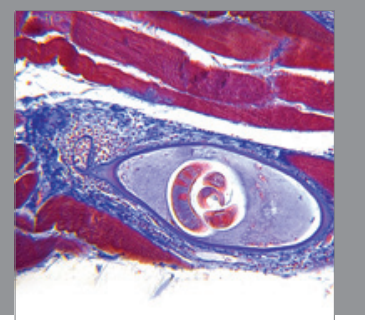

Gastroenterology

Research and Practice
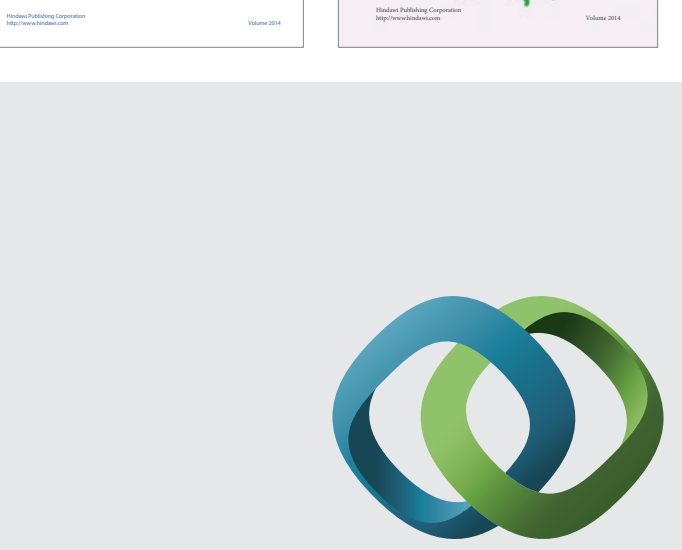

\section{Hindawi}

Submit your manuscripts at

http://www.hindawi.com
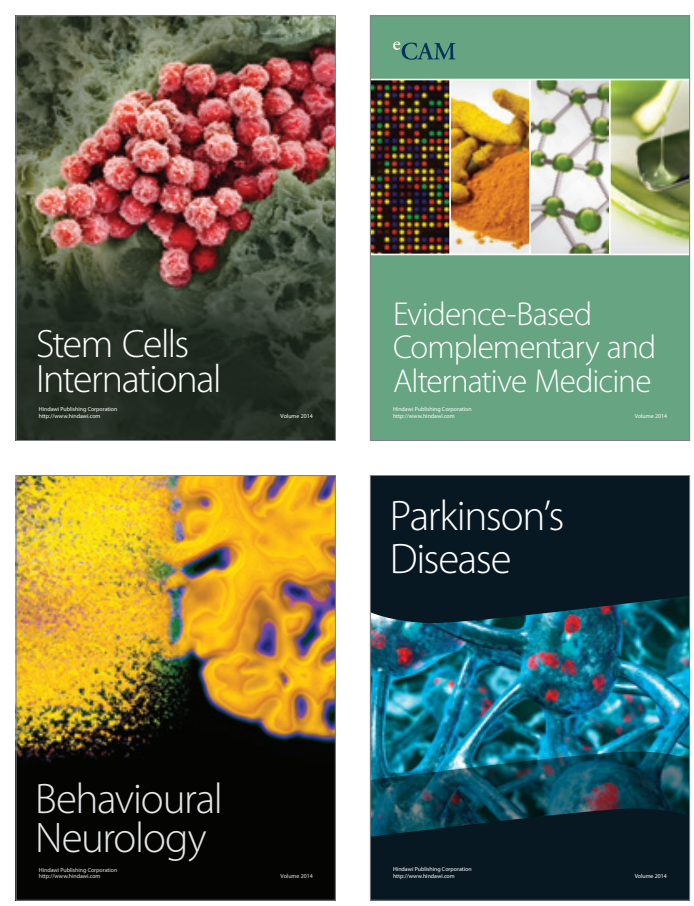

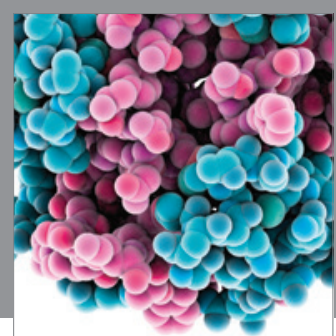

Journal of
Diabetes Research

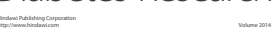

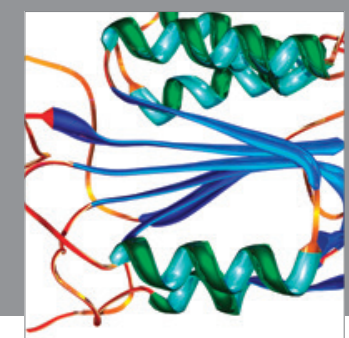

Disease Markers
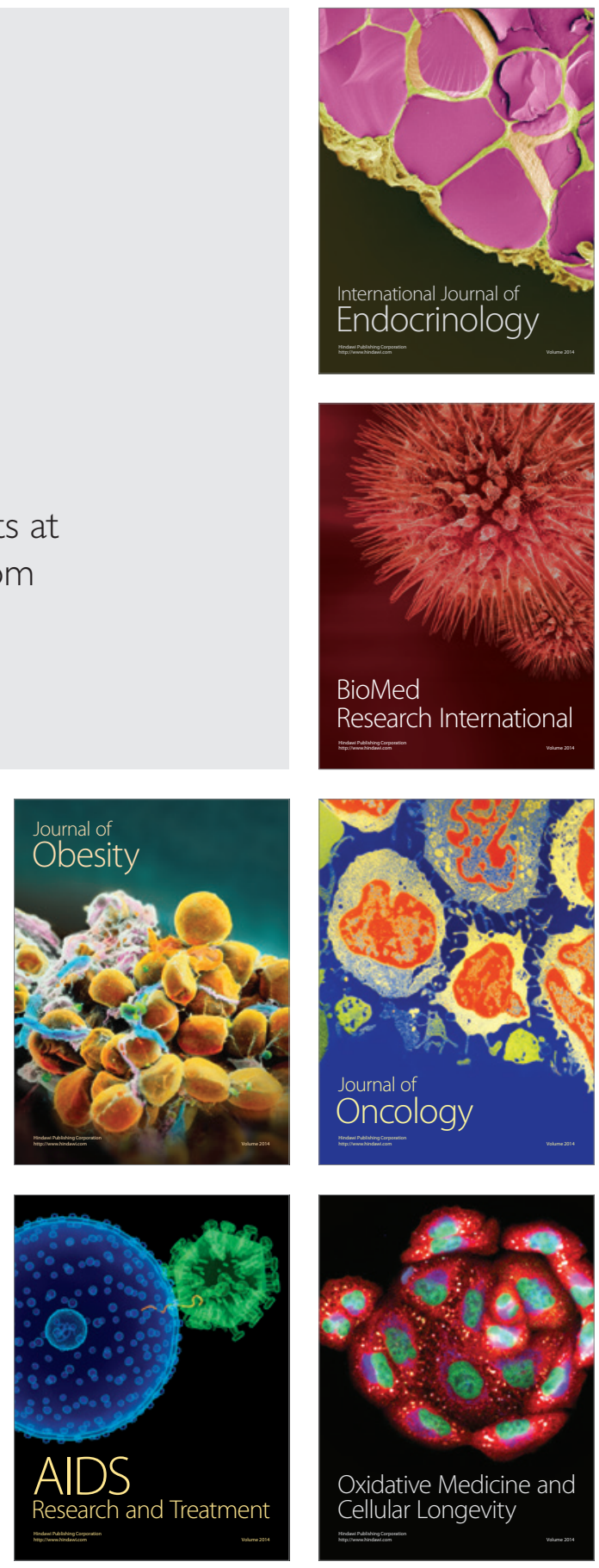